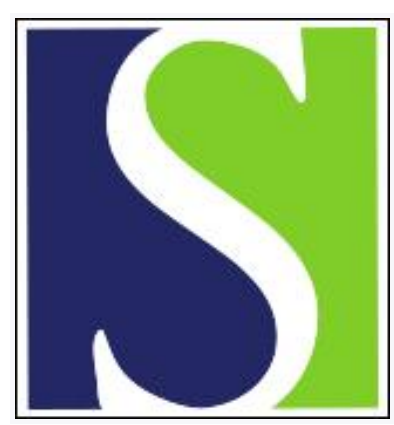

Scand J Work Environ Health 1991;17(6):392-397

https://doi.org/10.5271/sjweh.1688

Issue date: Dec 1991

Preemployment medical examinations in a large occupational health service.

by de Kort WL, Fransman LG, van Dijk FJH

Affiliation: Netherlands Organization for Applied Scientific Research TNO, Medical Biological Laboratory, Rijswijk.

The following article refers to this text: 2010;36(4):299-304

This article in PubMed: www.ncbi.nlm.nih.gov/pubmed/1788532 


\title{
Preemployment medical examinations in a large occupational health service
}

\author{
by Wim LAM de Kort, MD, ${ }^{1}$ Lou G Fransman, MD, ${ }^{2}$ Frank $\mathrm{JH}$ van Dijk, MD ${ }^{3}$
}

\begin{abstract}
de KORT WLAM, FRANSMAN LG, van DIJK FJH. Preemployment medical examinations in a large occupational health service. Scand J Work Environ Health 1991;17:392-7. Several hundreds of thousands of preemployment medical examinations are performed in The Netherlands each year, with the objective of screening for obvious risks for the applicants or others. Neither the efficacy of these examinations nor determinants for rejection are known. Altogether 101754 preemployment medical examinations of applicants for governmental functions were analyzed. For one-fifth of the applicants some medical diagnosis was recorded. The overall rejection percentage was $0.6 \%$, being highest for job categories involving public safety and high physical demands, but never exceeding $4 \%$. Age was positively correlated with rejection percentage. Except for the diagnostic category "disorders of the musculoskeletal system" no relation between diagnostic category and job demands was apparent. Medical diagnoses frequently encountered among rejected applicants were also common among successful applicants. If selection aiming at reducing absenteeism or work disablement is considered to be the only goal of preemployment medical examinations, then their efficacy appears to be low for many job categories.
\end{abstract}

Key terms: absenteeism, efficacy, health screening, personnel selection, prevention, work disablement.

The preemployment medical examination is generally viewed as important $(1-5)$, and many workers undergo a preemployment or preplacement medical examination as a part of the hiring and selection procedure. When the importance of these examinations is questioned, it is usually the procedure itself, legal aspects, or ethical aspects which are at issue (6-12). Its efficacy in terms of, for example, lowering absenteeism or reducing work-related diseases is not frequently discussed. When at issue, however, the conclusion is often reached that it is of little consequence (13). This conclusion is not surprising because, from theoretical considerations, it can be concluded that the preemployment medical examination cannot be highly effective. The methods used generally have a low sensitivity and specificity, and many of the disorders which they seek to disclose have low prevalences (14-15). Even when specific risk factors for occupational disease are analyzed, many false positive and false negative results can be expected, while the impact on the reduction of the ailment to be prevented remains limited. One example of this situation is the detection of atopic status

\footnotetext{
1 Netherlands Organization for Applied Scientific Research TNO, Medical Biological Laboratory, Rijswijk, The Netherlands.

2 Governmental Occupational Health and Safety Service, The Hague, The Netherlands.

3 University of Amsterdam, Faculty of Medicine, Coronel
} Laboratory, Amsterdam, The Netherlands.

Reprint requests to: Dr WLAM de Kort, Netherlands Organization for Applied Scientific Research TNO, Medical Biological Laboratory, PO Box 45, 2280 AA Rijswijk, The Netherlands. to reduce the incidence of laboratory animal allergy (16-19).

In order to assess governmental policy on preemployment medical examinations, the Directorate General of Labour of the Ministry of Social Affairs and Employment in The Netherlands decided to evaluate current practice in preemployment medical examinations. Within this framework an inventory was recently performed on the extent of preemployment medical examinations in The Netherlands and the results arising from these examinations (20). The inventory revealed that during the year 1988 some 300000 to 350000 preemployment medical examinations were performed: The costs of these medical examinations amounted to about 50 million Dutch guilders ( 30 million US dollars). According to this inventory these examinations resulted in the rejection of $1-2 \%$ of the applicants. However, in practice, the aims of the preemployment medical examination differed widely among physicians, ranging from the assessment of health risks to the applicant to the assessment of (economical) risks for the employer. Furthermore, the procedures did not appear to be uniform. The inventory did not give insight into the possible differences in rejection rates between job categories, into the medical diagnoses leading to acceptance or rejection, or into other determinants for rejection such as age or gender. However, the discussion on efficacy of preemployment medical examinations would be served by quantitative data on determinants of preemployment examination results.

Therefore, to increase insight into the determinants of preemployment medical examination results, a second study, with an appropriate well-documented popu- 
lation, was considered necessary. This paper reports on the results of this second study.

\section{Subjects and methods}

In The Netherlands, with a working population of about six million people, there are approximately 210000 civil servants, distributed over 14 ministries: the ministries of general affairs (1000 persons), home affairs ( 4000 persons), foreign affairs (5000 persons), economic affairs ( 6000 persons), finance ( 35000 persons), social affairs and employment ( 8000 persons), welfare, public health and cultural affairs ( 8000 persons), defence (civil personnel only: 28000 persons), education and science (37000 persons), housing, physical planning and environment ( 8000 persons), justice (35 000 persons), agriculture and fisheries (17 000 persons), transport and public works (17000 persons), and developmental cooperation (1000 persons).

The Governmental Occupational Health and Safety Service provides occupational health services for all civil servants in The Netherlands. The Service has about 350 employees, including 100 hundred occupational health physicians. About 90 of these are directly involved in providing occupational health care, including the performance of preemployment medical examinations.

After applicants are considered suitable for a job by a selection committee, they go to the Service for a medical examination. The preemployment medical examination is obligatory for civil servants, and the result is used as a criterion for pension provisions. Nevertheless, it is formally accepted by the Service that the primary function of this medical examination is to assess the fitness of the applicant for the job. But examination results can also be used for future occupational health service activities, and fitness for the job automatically implies acceptance by the pension fund.

A guidance book written by the Governmental Occupational Health and Safety Service on preemployment medical examinations and medical selection criteria is available to the physicians. However, only when public safety is involved are explicit criteria for rejection or acceptance given. For all other jobs these criteria are formulated only in general terms. The philosophy of the preemployment medical examination is to screen against obvious health risks for the applicant or others.

Every preemployment medical examination follows the same procedure. The applicant fills out a comprehensive health questionnaire before he or she is seen by the staff of the Service. Standard biometrical data (eg, height, weight, blood pressure, perceptive acuity) are recorded for each applicant. The physician carries out a standard general medical examination. In selected cases additional tests (eg, an audiogram, spirometry, or an electrocardiograph) are performed. The physician summarizes the findings of the medical diagnoses, which are coded according to a standard code list. The diagnoses are ranked by the physician in such a manner that the first diagnosis is considered to be the most important with regard to the preemployment medical examination. After weighing the health data obtained against the data on the work environment, the physician decides on rejection or acceptance. This final decision of the physician is recorded on a separate form.

All the results are filed in a personal record. In addition to administrative data, the following results are coded and filed in an automated file: gender, birth date, job title, date of examination, medical diagnoses, and final decision.

The code for job title is assessed according to the function and job demands. The Service has a code book for this purpose. The number of different functions amounts to several thousands, grouped into the following 13 job categories: administrative, public safety (federal police and customs), custodial (eg, prison officers), security guards (security of property including buildings), patient care, (other) medical and paramedical personnel, education and teaching, transport, technical staff, (technical) maintenance, agriculture, cleaning and catering, and other (including specialized functions).

Functions have been grouped into these categories from function descriptions (including task description and - broadly formulated - data on the work environment) that are available for virtually every function because salary level depends to some extent on this description. Within each category functions show a similar spectrum of job demands. Exceptions to this rule are the categories "other medical and paramedical personnel" and "other personnel, including specialized functions." The spectrum of job demands between job categories can differ greatly.

For the medical diagnosis a three-digit code is used, grouped into categories. The coding resembles that of the International Classification of Diseases (ICD), but it does not match the ninth revision of the ICD coding precisely. In this study the following 17 diagnostic categories have been used: infectious diseases, neoplasms, thyroid disorders/diabetes mellitus, over- or underweight, psychological/psychiatric disorders, nervous system disorders, visual/auditory disorders, cardiovascular disorders, respiratory tract disorders, gastrointestinal disorders, urinary tract disorders, pregnancy, other hormonal disorders, disorders of the skin and skin appendices, musculoskeletal system, congenital disorders, other disorders.

For descriptive statistics BMDP (biomedical data package) statistical software was used on a VAX-8250 computer. For the logistic model the feature, available in the SPSS-PC 3.1 version (SPSS = Statistical Package for the Social Sciences), was used in which categorical variables with more than two values can be defined. P-values smaller than 0.05 were considered statistically significant. 
Table 1. Age distribution of all the applicants and the rejected applicants and the percentage of rejected applicants within respective age categories.

\begin{tabular}{|c|c|c|c|c|c|}
\hline \multirow{2}{*}{$\begin{array}{l}\text { Age category } \\
\text { (years) }\end{array}$} & \multicolumn{2}{|c|}{ All applicants } & \multicolumn{2}{|c|}{ Rejected applicants } & \multirow{2}{*}{$\begin{array}{l}\text { Percentage } \\
\text { rejected appli- } \\
\text { cants within } \\
\text { age category }\end{array}$} \\
\hline & $\mathbf{N}$ & $\%$ & $\mathbf{N}$ & $\%$ & \\
\hline $\begin{array}{l}<20 \\
20-29 \\
30-39 \\
40-49 \\
>49\end{array}$ & $\begin{array}{r}5042 \\
65171 \\
22295 \\
7140 \\
2106\end{array}$ & $\begin{array}{r}5.0 \\
64.2 \\
21.9 \\
7.0 \\
2.0\end{array}$ & $\begin{array}{r}27 \\
277 \\
165 \\
105 \\
35\end{array}$ & $\begin{array}{r}4.4 \\
45.5 \\
27.1 \\
17.2 \\
5.7\end{array}$ & $\begin{array}{l}0.5 \\
0.4 \\
0.7 \\
1.5 \\
1.7\end{array}$ \\
\hline Total & 101754 & 100 & 609 & 100 & 0.6 \\
\hline
\end{tabular}

Table 2. Distribution and number of rejections according to job category and the percentage of rejections within each category.

\begin{tabular}{lrrr}
\hline \multirow{2}{*}{ Job category } & $\begin{array}{c}\text { All } \\
\text { applicants } \\
(\mathrm{N})\end{array}$ & \multicolumn{2}{c}{ Rejections } \\
\cline { 3 - 5 } & 41618 & 132 & 0.3 \\
\hline Administration & 2252 & 49 & 2.2 \\
Police/customs & 3504 & 110 & 3.1 \\
Prison officers & 2170 & 44 & 2.0 \\
Security guards & 4452 & 29 & 0.7 \\
Nursing & 4798 & 6 & 0.1 \\
Physicians and & 11221 & 9 & 0.1 \\
other paramedical workers & 1987 & 31 & 1.6 \\
Teaching & 5004 & 12 & 0.2 \\
Transport & 3915 & 30 & 0.8 \\
Technical staff & 2053 & 19 & 0.9 \\
Maintenance & 3479 & 48 & 1.4 \\
Agriculture & 15301 & 90 & 0.6 \\
Cleaning/catering & 101754 & 609 & 0.6 \\
Other & & &
\end{tabular}

\section{Results}

In the period of investigation, the six-year time period from 1 January 1983 to 31 December 1988, a total of 105723 requests for preemployment medical examinations was presented to the Governmental Occupational Health and Safety Service. Of the persons to be examined, 269 appeared to have been recently examined by another physician, and in 415 cases $(0.4 \%)$ there was no final result for various reasons, mainly incompleteness of data. Of the remaining 105039 requests, $3285(3.1 \%)$ were withdrawn before completion of the procedure. It was decided to omit the latter category from further analyses after a random sample failed to reveal any medical reason for withdrawal. However, some unidentified bias may have been introduced since the records may have included applicants who have - in consultation with the physician - withdrawn themselves from the selection procedure for medical reasons. Such an outcome is not noted in the file.
For further analysis 101754 cases with complete data remained, $59441(58.4 \%)$ men and 42313 $(41.6 \%)$ women. The (arithmetic) mean age of all the applicants was 27.5 (SD 7.7) years. In 609 cases $(0.60 \%)$ the applicant was rejected, 411 men $(0.69 \%)$ and 198 women $(0.47 \%)$. These data suggest that men are liable to be rejected 1.48 times more frequently than women, a statistically significant result. However, a greater number of male applicants sought jobs with higher rejection percentages, such as police officer/ customs, guard, transport, or maintenance. Almost $25 \%$ of the male applicants in this study had applied for jobs in these sectors, compared with less than $10 \%$ of the female applicants. When the rejection rates for the male applicant population are standardized with female job category frequencies as a standard, the ratio of 1.48 decreases to 1.19 , which is still statistically significant. When, analogous to the gender-related job preference standardization, a standardization is performed for gender-related differences in diagnosis frequencies, the ratio of 1.48 decreases to 1.25 , also still statistically significant. Stratifying and then standardizing the results over these two factors together was not feasible due to the many empty cells in this threedimensional matrix.

The mean age of the rejected applicants was 31.5 (SD 9.9) years. The difference in age between the rejected and successful applicants was statistically significant $(\mathrm{P}<0.001)$, and the percentage of rejected applicants rose with increasing age (table 1).

The percentage of rejections diverged substantially between job categories, being highest for job categories in which (public) safety and/or physical demands (prison officers, police and customs, security personnel, transport) play a significant role and being lowest for job categories without significant safety aspects or physical demands (teaching personnel, technical staff, administrative personnel) (table 2).

Some diagnostic categories were more frequent among the rejected candidates than other diagnostic categories (table 3). For example, disorders of the musculoskeletal system, of the visuoauditory system or psychological/psychiatric disorders were diagnosed the most frequently. However table 3 shows another important feature. Many of the disorders frequently diag- 
Table 3. Distribution over diagnostic categories.

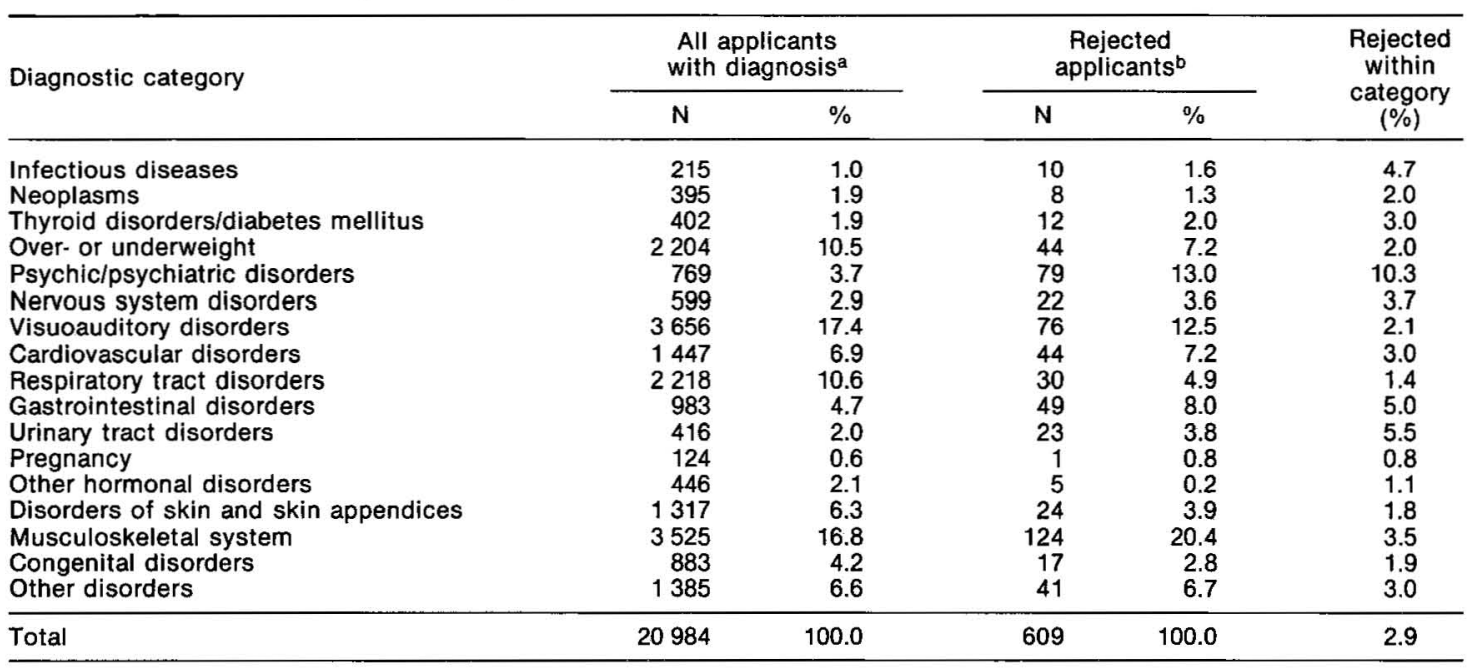

a For 20984 cases $(20.1 \%$ of all applicants) some diagnosis was made.

b For all the rejected applicants a diagnosis was made.

nosed among the rejected applicants were also frequently diagnosed among applicants who were not rejected. The last column of table 3 shows the percentage of applicants rejected within a diagnostic category. It can be seen that the variation of the rejection percentage over categories is much smaller. There was one apparent exception. If a diagnosis was made which belongs to the category psychological/psychiatric disorders, the applicant was far more likely to be rejected, when compared with applicants with diagnoses from other categories. Collapsing table 3 into a $2 \times 2$ table (rejected/not rejected versus psychological, psychiatric disorder/other disorder) a diagnosis from this category brings with it an odds ratio of 3.8 for being rejected, compared with other diagnostic categories. The analogous odds ratio for being rejected with the diagnosis "disorder of the musculoskeletal system," the most frequent diagnosis among rejected applicants, was only 1.2.

The similarity of the frequency distribution over the diagnostic categories among the rejected and successful applicants does not change much if these frequencies are compared within different job categories. However, cell frequencies become very small. Only one diagnostic category, namely, disorders of the musculoskeletal system, shows differences in rejection percentages between job categories that can be understood in terms of differences in job demands, as is shown in table 4. The highest percentages of rejections with the diagnosis musculoskeletal system disorder were found in job categories in which physical job demands were higher than average (police/customs, security personnel, nursing, and cleaning/catering personnel). For other diagnostic categories such a relationship only occasionally showed up, for example, the diagnosis of skin disorder was made relatively frequently among rejected nurses.
Table 4. Number and distribution of rejections with a diagnosis in the diagnostic category musculoskeletal disorder, according to job category.

\begin{tabular}{lcrr}
\hline Job category & $\begin{array}{c}\text { All applicants } \\
\text { with diagnosis of } \\
\text { musculoskeletal } \\
\text { disorder } \\
(\mathrm{N})\end{array}$ & $\begin{array}{c}\text { Rejected applicants } \\
\text { with diagnosis of } \\
\text { musculoskeletal } \\
\text { disorder }\end{array}$ \\
\cline { 3 - 4 } & 1392 & $\mathrm{~N}$ & $\% \%^{\mathrm{a}}$ \\
\hline Administration & 48 & 6 & 1.0 \\
Police/customs & 221 & 31 & 14.5 \\
Prison officers & 96 & 8 & 8.3 \\
Security guards & & & \\
Physicians and & 144 & 2 & 1.4 \\
other paramedical & 116 & 10 & 8.6 \\
workers & 393 & 2 & 0.5 \\
Nursing & 64 & 5 & 7.8 \\
Teaching & 179 & 2 & 1.1 \\
Transport & 154 & 6 & 3.9 \\
Technical staff & 70 & 5 & 7.1 \\
Maintenance & 137 & 18 & 13.1 \\
Agriculture & 511 & 15 & 2.9 \\
Cleaning/catering & 3525 & 124 & 3.5 \\
Other & & & \\
\hline Total & & &
\end{tabular}

a Rejections within a job category.

To determine whether the examination outcome (rejected or not) could somehow be predicted from this data set, a logistic regression model was set up using the outcome as the dependent variable and age, gender, job categories, and diagnostic categories as independent variables. The model, as applied to the subset of 20984 cases with a diagnosis of any kind, gave no satisfactory fit, and it had a low internal (negative) predictive power (ie, none of the rejections could have been predicted by the model on the basis of the applicants' data set. The rarity of a negative outcome (being rejected) may have contributed to this result. It is true, 
however, that the model did indeed yield a statistically significant (but apparently not very useful) improvement in the prediction of the examination outcome and that the variable gender gave no significant contribution $(P>0.05)$. The latter finding gives further support to the suggestion that no significant gender-related rejection difference existed.

\section{Discussion}

The study population should not be regarded as representative of the whole Dutch working population. Many specific jobs in industry or in the building trade have no counterpart in the governmental branch and vice versa. However, many of the same types of jobs can be encountered in a large part of all work sectors [eg, the (lower) administrative functions, the transport functions, the maintenance functions, and the cleaning/catering functions, comprising more than half of this study population], and they are commonly found outside the governmental branch. In view of the external validity of the results of this study it is important to note that the Governmental Occupational Health and Safety Service is the largest occupational health service in The Netherlands. It functions in a manner comparable with many occupational health services outside the governmental branch, especially those occupational health services which include monitoring of sick leave in their care provision. The occupational physicians of the Service have had the same training as their colleagues in other occupational health services. Tasks (including preemployment medical examinations) of occupational health services in The Netherlands have a legal basis in the Working Environment Act of 1983, although occupational health services are not generally obligatory. As mentioned before, preemployment medical examinations are obligatory for civil servants; however, fitness for the job remains the formally accepted primary function of the preemployment medical examination within the Governmental Occupational Health and Safety Service. We have concluded that, with the restriction of differences in types of jobs, our results can be viewed as meaningful to nongovernmental branches of work.

The number of rejections was very small, and only a few job categories showed rejection percentages that exceeded $1 \%$. When public safety was involved and/or physical demands were part of the spectrum of job demands, the rejection percentage was higher, but it never exceeded $4 \%$. It was noted that only for those jobs in which public safety is involved are criteria for rejection or acceptance explicitly available. There were no data available from which it could be concluded to what extent self-selection or selection by the personnel departments was responsible for the low rejection percentages.

Age appeared to be a determinant for rejection, applicants over 50 years of age having about a fourfold increased risk of being rejected, compared with colleagues in their 20 s.

Although raw data showed men to be rejected about 1.5 times as frequently as women, gender appeared to be no determining factor. Much of this discrepancy disappeared when the results were adjusted to account for the fact that men often applied for specifically physically demanding jobs or security jobs, jobs known to have higher rejection percentages. The discrepancy was also attributable, though to a less extent, to the fact that the men had a different diagnosis profile. It is therefore likely that a difference in rejection percentage between male and female applicants, if it exists, is small and without important consequences.

Although some diagnoses appeared more frequently among rejected applicants, the same diagnoses were found in similar frequency distributions among applicants who were not rejected. This finding leads to the suggestion that the job category is a much stronger determinant for rejection than is a medical diagnosis. However, from the available data the severity of the disease/disorder diagnosed could not be assessed. In this respect, we suggest that the acceptability of severity is determined more strongly by the job category than by the medical diagnosis itself. In every diagnostic category approximately the same percentage of cases is rejected, the job category determining the level of this percentage. An apparent exception to this rule is the diagnosis psychological/psychiatric disturbances, which is made 3.5 times more frequently among rejected applicants as compared with the subpopulation of successful applicants with this diagnosis.

On the basis of these results alone it can be stated with some certainty that for those job categories with a low rejection percentage (eg, $<1 \%$ ) the preemployment medical examination adds little if anything to the recruitment selection of new personnel. Still, it may be considered important to identify the small category of applicants that must be judged to be unfit for the job. Then, however, a reproducible, standardized and valid examination is urgently desirable. The general appearance of such examinations must be doubted seriously (21) and is currently being investigated.

If selection aiming at reducing absenteeism or work disablement is to be the only reason for preemployment medical examinations for job categories with low rejection percentages, it would appear to be tempting to end this practice. An alternative approach would be to pay more attention to the possibility of providing information to applicants (eg, about health risks of the job and about possibilities for prevention) before any selection procedure is started. However, this study also showed that in about $20 \%$ of the cases some kind of medical diagnosis could be made. The large majority of these diagnoses do not imply the decision "unfit for the job," but may on the other hand provide the starting point for a tailor-made occupational health service to include, among other features, proper and 
individualized adjustments of work tasks or work environments.

\section{Acknowledgments}

This study was supported by a grant from the Directorate General of Labour of the Ministry of Social Affairs and Employment, Voorburg, The Netherlands.

Part of the results of this study were presented at the 23rd International Congress on Occupational Health in Montreal, Canada, in September of 1990.

The authors wish to thank Dr E Lourijsen and Dr J Radder from The Netherlands Institute for Preventive Health Care TNO in Leiden for their remarks and support.

\section{References}

1. Schussler T, Kaminer AJ, Power VL, Pomper IH. The preplacement examination. J Occup Med 1975;17: 254-7.

2. Hogan JC, Bernacki EJ. Developing job-related preplacement medical examinations. J Occup Med 1981; 23:469-76.

3. Health and Safety Executive. Pre-employment health screening. London: Health and Safety Executive, 1982. (Guidance note MS20.)

4. Cowell JWF. Guidelines for fitness-to-work examinations. Can Med Assoc J 1986;135:985-8.

5. Schilling RSF. The role of medical examination in protecting worker health. J Occup Med 1986;28:553-7.

6. Todd JW. Pre-employment medical examination. Lancet 1965;1:797-9.

7. Royal Dutch Society for the Promotion Health Care. Wat mag en moet bij een aanstellingskeuring [What is allowed and should be done in a pre-employment health examination]. Med Contact 1980;35:849-54.

8. Lappé MA. Ethical issues in testing for differential sensitivity to occupational hazards. J Occup Med 1983;25:
797-808.

9. Atherley G, Human rights versus occupational medicine. Int J Health Serv 1983;13:265-75.

10. Kelman GR. The pre-employment medical examination. Lancet 1985;2:1231-3.

11. Rothstein MA. Discriminatory aspects of medical screening. J Occup Med 1986;28:924-9.

12. Floyd M, Espir MLE. Assessment of medical fitness for employment: the case for a code of practice. Lancet 1986;2:207-9.

13. Alexander RW, Brennan JC, Maida AS, Walker RJ. The value of preplacement medical examinations for nonhazardous light duty work. J Occup Med 1977;19: 107-12.

14. Galen RS, Gambino SR. Beyond normality: the predictive value and efficiency of medical diagnoses. New York, NY: John Wiley \& Sons, 1975.

15. Weinstein MC, Fineberg HV. Clinical decision analysis. Philadelphia, PA: WB Saunders Company, 1980.

16. Nordman H. Atopy and work. Scand J Work Environ Health 1984;10:481-5.

17. Newill CA, Evans R, Khoury MJ. Pre-employment screening for allergy laboratory animals: epidemiologic evaluation of its potential usefulness. J Occup Med 1986;28:1158-64.

18. Botham PA, Davies GE, Teasdale EL. Allergy to laboratory animals: a prospective study of its incidence and of the influence of atopy on its development. $\mathrm{Br} \mathrm{J}$ Ind Med 1987;44:627-32.

19. Slovak AJM, Hill RN. Does atopy have any predictive value for laboratory animal allergy? Br J Ind Med 1987; 44:129-32.

20. Lourijsen ECMP, Hoolboom H, Kort WLAM de. De aanstellingskeuring: een beschrijvend onderzoek [The pre-employment medical examination: an inventory]. Voorburg: Directorate General Labour, 1989. (Study series; no 53-1.)

21. Blesgraaf E, Groenendijk M, Lange $\mathrm{H}$ de, Moelands $\mathrm{C}$. Uniformiteit bij aanstellingskeuringen [Uniformity in pre-employment medical examinations]. Tijdschr Soc Gezondh 1986;64:139-43. (English abstract.)

Received for publication: 21 February 1991 